\title{
Cytotoxic Effects of Three Denture Base Materials on Gingival Epithelial Cells and Fibroblasts: An in vitro Study
}

${ }^{1}$ Swati Ahuja, ${ }^{2}$ Jegdish Babu, ${ }^{3}$ Russell Wicks, ${ }^{4}$ Franklin Garcia-Godoy, ${ }^{5}$ David Tipton

\section{ABSTRACT}

Objectives: Modern polyamide 'flexible' denture base materials have increased in popularity for use in removable partial dentures. The introduction of these new products warrants investigation of their relative potential for toxicity. The purpose of this study was to investigate three contemporary denture base materials used in fabricating definitive prosthetic restorations.

Materials and methods: Two 'flexible' materials (Valplast ${ }^{\mathrm{TM}}$ and Duraflex ${ }^{\mathrm{TM}}$ ) formed by thermoplastic injection molding technique, and one traditional heat processed, methyl methacrylate resin material (Lucitone 199) were evaluated. Cultured gingival epithelial cells and fibroblasts were treated with conditioned media prepared from denture material disks and then assayed for cell toxicity by [3-(4,5-dimethylthiazol2-yl)-2,5-diphenyltetrazolium bromide] (MTT) cell viability assay. Cell membrane damage was determined by measuring the release of cytoplasmic lactate dehydrogenase. Further confirmation of toxicity induced by the conditioned media was determined by staining the cells with live/dead stain and observing under a UV microscope.

Results: Data were analyzed by means of a linear model ANOVA followed by Tukey's post hoc tests for comparison among groups. The significance level adopted was 5\% ( $p<$ $0.05)$. The three denture materials differed in their toxicity to the cells as assessed by MTT assay. Valplast conditioned media in general, especially the media of unpolished disks, was found to be toxic to both gingival fibroblasts and epithelial cells while media obtained from polished Lucitone and Duraflex were found to be less toxic. After 7 days of incubation with Valplast unpolished conditioned media, only 1 to $2 \%$ of the cells remained viable, while the polished disk conditioned media caused significantly less $(p<0.05)$ toxicity, approximately 76 and $92 \%$ of fibroblasts and epithelial cells respectively, were viable. After 7 days of incubation with media obtained from the other denture materials, 35 to $92 \%$ of fibroblasts and epithelial cells were found to be viable. The data obtained from lactate

\footnotetext{
${ }^{1}$ Adjunct Assistant Professor, ${ }^{2}$ Associate Professor

${ }^{3}$ Professor and Chair, ${ }^{4}$ Professor and Senior Executive

${ }^{5}$ Professor

${ }^{1,3}$ Department of Prosthodontics, University of Tennessee TN, United States

2,4,5 Department of Bioscience Research, University of Tennessee, TN, United States
}

Corresponding Author: Swati Ahuja, Adjunct Assistant Professor, Department of Prosthodontics, University of Tennessee, TN, United States, Phone: 9014486101, e-mail: sahuja@uthsc.edu dehydrogenase (LDH) assay and live/dead mammalian cell viability assay were in agreement with the MTT viability assay.

Conclusion: Conditioned media from unpolished Valplast denture material appeared to be significantly more toxic to gingival fibroblasts and epithelial cells when compared to the polished Lucitone disk conditioned media as well as the media obtained from Duraflex.

Keywords: Valplast, Cytotoxicity, Dentures, Polyamide.

How to cite this article: Ahuja S, Babu J, Wicks R, GarciaGodoy F, Tipton D. Cytotoxic Effects of Three Denture Base Materials on Gingival Epithelial Cells and Fibroblasts: An in vitro Study. Int J Experiment Dent Sci 2015;4(1):11-16.

Source of support: This study was supported by a research grant from the University of Tennessee, College of Dentistry Alumni Endowment Fund and Tennessee Dental Association Foundation.

\section{Conflict of interest: None}

\section{INTRODUCTION}

Denture base materials have been developed and refined over the last century. Early commercial products included Vulcanite (a vulcanized rubber), which could be molded to specific shapes to replace the missing gingival architecture of an edentulous patient. This material was sturdy in the oral environment and generally biocompatible with the residual mucosa. In the 1940s, the development of polymethyl methacrylate resins which possessed greater esthetic quality, repair ability and superior physical properties eventually usurped the vulcanized rubber materials in the denture base market. ${ }^{1}$ Biologic tests are not required by materials safety standard regulations for the use of denture base products. They are considered low risk materials for patients' health. ${ }^{2}$ Nevertheless, concerns regarding the release of residual monomer and other eluates (including formaldehyde, plasticizers, benzyl peroxide, etc.) into the oral environment have been raised. They may cause mucosal irritation and sensitization of the oral tissues. ${ }^{3-9}$ Clinical symptoms include burning sensation in the mouth, redness, vesicles, ulceration, swelling and edema. ${ }^{10}$ Previous studies have confirmed that resin materials are potentially toxic to various degrees based on their specific composition, ${ }^{11}$ porosity, type of polymerization reaction, ${ }^{12,13}$ technique used for polymerization ${ }^{14}$ and post polymerization material handling. 15,16 
More recently, polyamide materials, which are formed thermally and not chemically processed, have been widely promoted for use as a denture base. Particularly, advocated for these materials are properties including biological inertness, flexibility and the elimination of a metallic framework for applications in partial dentures. ${ }^{17}$ Little information about these denture base polymers has been published in the scientific literature, despite their widespread use. It is crucial to investigate the cytotoxic potential of these newer materials so that a material with the least toxicity can be selected.

Removable prosthetics routinely have two basal surfaces. The detail from the master cast of the patient is preserved on the intaglio surface. It is not finished or polished during the construction process as this surface must fit in intimate contact with the residual ridge tissue supporting the denture base. The cameo or external surface of the prosthesis is highly polished and represents the replacement of the teeth and supporting structures which contact the tongue and cheek. ${ }^{18}$ The objectives of this study were (1) to determine the potential toxicity of three denture base materials to human gingival epithelial cells and fibroblasts, (2) to compare the relative toxicity of the three materials and (3) to compare the relative toxicity of the polished (P) and unpolished surfaces (UP). The null hypothesis of this study was that there is no statistically distinguishable $(p>0.05)$ difference in the relative viability of epithelial cells and fibroblasts exposed to the three denture base materials, polished and unpolished.

\section{MATERIALS AND METHODS}

Denture disk sample preparation: Sixty-four sample disks (approximately $8 \mathrm{~mm}$ in diameter $\times 2 \mathrm{~mm}$ thick) of each test denture material were prepared according to the manufacturer's instructions. These included: (1) heat polymerized polymethyl methacrylate (Lucitone 199, Dentsply) (2) thermoformed nylon 6 polyamide (Valplast ${ }^{\mathrm{TM}}$, Valplast International), and (3) thermoformed nylon 12 composite polyamide (Duraflex ${ }^{\mathrm{TM}}$, Myerson). The surfaces of half of the specimens of each denture material (both the flat surfaces and the edges) were finished and polished as a cameo prosthetic surface with pumice and Acriluster (Buffalo Dental Manufacturing Co.), rinsed with tap water and air dried. The other half of the samples of the denture materials were left unpolished to represent an intaglio prosthetic surface. The samples were obtained from the manufacturer within 24 hours of their preparation and tested within 4 days. The disks were sterilized with ethylene oxide gas and rinsed thoroughly with sterile deionized water prior to their use in the study. All experiments were performed with triplicate disk samples, and each experiment was repeated at least three times.

Human gingival epithelial cells: Human gingival epithelial cells (S-G) were obtained from FH Kasten, East Tennessee State University, Quillen College of Medicine, Johnson City, TN. The cells were grown in Dulbecco's Modified Eagle Medium (DMEM; Gibco), supplemented with 10\% (v/v), newborn calf serum (Gibco) and $100 \mu \mathrm{g} / \mathrm{ml}$ gentamicin (Sigma-Aldrich) (termed growth medium) at $37^{\circ} \mathrm{C}$ in a humidified atmosphere of $5 \% \mathrm{CO}_{2}$ in air for 24 hours. The S-G cells are a stable cell line with trisomic chromosome distribution and retention of epithelial-like morphology. ${ }^{19,20}$ One milliliter of cell suspension containing $1 \times 10^{5}$ cells were placed in each well of a 48 well culture dish and incubated at $37^{\circ} \mathrm{C}$ in $5 \% \mathrm{CO}_{2}$ in air for 24 hours to allow the cells to adhere. The following day the media containing nonadherent cells was discarded and the adherent cells were replenished with fresh growth media and used in the toxicity studies.

Human gingival fibroblasts: Normal human gingival fibroblasts, derived from gingival explants from healthy individuals with noninflamed gingiva using standard techniques, were previously established in laboratory. ${ }^{21}$ The cells were routinely grown in growth medium at $37^{\circ} \mathrm{C}$ in a humidified atmosphere of $5 \% \mathrm{CO}_{2}$. One milliliter of cell suspension containing $1 \times 10^{5}$ cells were placed in each well of a 48 well culture dish and incubated at $37^{\circ} \mathrm{C}$ in $5 \% \mathrm{CO}_{2}$ in air for 24 hours to allow the cells to adhere. As described above, nonadherent cells were discarded by changing the media and the adherent cells were utilized in the study.

Preparation of denture-disk conditioned media: Five groups of denture disks in triplicates, were incubated with $2.5 \mathrm{ml}$ of DMEM growth media in a 24-well culture dish, sealed with parafilm to minimize the media evaporation, at $37^{\circ} \mathrm{C}$ in a humidified atmosphere of $5 \% \mathrm{CO}_{2}$ in air. The media was collected from each individual group on, ${ }^{2-5}$ and 7 days and kept frozen at $-20^{\circ} \mathrm{C}$ until all the samples were collected. Growth media without denture disks were incubated in a similar manner and served as control media.

Determination of denture material cytotoxicity by [3-(4,5-dimethylthiazol-2-yl)-2,5-diphenyltetrazolium bromide] (MTT) cell viability assay: Effects of the denture material conditioned media on cell viability was assessed by MTT assay, which is based on the ability of the mitochondrial enzyme, succinate dehydrogenase to cleave the tetrazolium salt [3-(4, 5-dimethylthiazol-2-yl)-2,5-diphenyl tetrazolium bromide] (MTT) to a formazan dye by metabolically active cells, using a MTT kit from Roche laboratories (Roche Diagnostics.) 
In order to test the effect of conditioned media obtained from denture disks on cell viability, an aliquot $(0.2 \mathrm{ml}$ in triplicate) of control or denture disk conditioned media was added to the wells seeded with $1 \times 10^{5}$ fibroblasts or epithelial cells in a 48 -well dish along with fresh $1.0 \mathrm{ml}$ of growth media and incubated for 24 hours at $37^{\circ} \mathrm{C}$. Following the incubation, cell viability was tested by adding $0.1 \mathrm{ml}$ of MTT label provided in the manufacturer's kit and incubating for 2 hours at $37^{\circ} \mathrm{C}$. Purple formazan crystals produced from the MTT by metabolically active cells was solubilized by overnight incubation with solubilization solution provided in the manufacturer's kit, at $37^{\circ} \mathrm{C}$. Aliquots of $200 \mathrm{ml}$ were removed and dispensed to a clean 96-well plate, and absorbance read at $550 \mathrm{~nm}$ using a microtiter plate spectrophotometer (Spectrostar; BMG Lab Tech Inc). The resultant optical density is directly proportional to the number of viable cells. Results were expressed as $\%$ control $\left(\mathrm{A}_{550 \mathrm{~nm}}\right.$ in cells exposed to control growth media alone).

Effect of the denture-material conditioned media on cell membrane integrity measured by lactate dehydrogenase $(\mathrm{LDH})$ assay: Cytotoxicity of the materials leading to plasma membrane damage was measured using the cytotoxicity detection kit lactate dehydrogenase (LDH) (Roche Diagnostics). Lactate dehydrogenase, a stable cytoplasmic enzyme found in all cells, is quickly released upon damage to the plasma membrane. ${ }^{22,23}$ Individual wells of a 48 -well culture plate were seeded with fibroblasts or epithelial cells containing $1 \times 10^{5}$ cells $/ \mathrm{ml}$ and allowed to adhere. A low serum concentration was used to reduce background absorbance because animal sera contain various levels of $\mathrm{LDH}$; and 1\% serum is sufficient for these cells to attach, and does not add significantly to LDH activity released by the cells. After attachment, the medium was removed from the wells, and washed once with $2 \mathrm{ml}$ phosphate buffered saline (PBS), and then $1 \mathrm{ml}$ denture disk conditioned media or control media was added, and incubated for 24 hours. To determine maximum LDH release (high control), in some wells the cells were solubilized with a final concentration of $1 \%(\mathrm{w} / \mathrm{v})$ Triton X-100 (Sigma- Aldrich). Spontaneous LDH release (low control) was determined by incubating the cells with the media alone. The cell-free supernatants were collected and transferred to clean 96-well plates. Lactate dehydrogenase activity was assayed in the supernatants by a reaction in which the tetrazolium salt, INT, was reduced to a red formazan salt, using the LDH cytotoxicity detection kit. Since the cells were incubated for 24 hours, the LDH release serves as a general cytotoxicity assay. Absorbance was read at $490 \mathrm{~nm}$ with Spectrostar spectrophotometer. Results were expressed as \% cytotoxicity [(experimental value-low control/high control-low control) $\times 100$ ] .
Cytotoxic effect of the denture materials conditioned media on epithelial cells determined by live/dead mammalian cell viability assay: Cytotoxicity of cultured epithelial cells following the exposure to denture base materials was measured using the live/dead mammalian cell viability assay kit (Molecular Probes, Invitrogen). Epithelial cells were incubated with denture disk condition media as described previously for 24 hours. Cells were rinsed with saline and incubated with the fluorescent dye mixture provided in the kit, prepared according to the manufacturer's instructions for 15 minutes, and washed with saline. The green fluorochrome (SYTO 9) penetrates intact membranes, while the larger red fluorochrome (propidium iodide) penetrates only dead cells, resulting in red fluorescence by binding to nuclear material of the cells. The cells were then viewed under a fluorescent microscope (Leitz) to examine the cells.

\section{RESULTS}

Each experiment was repeated a minimum of three times, with triplicate determinations at each data point. Mean values \pm SE were calculated and the data obtained were analyzed by means of a linear model ANOVA followed by Tukey's post hoc tests for comparison among groups. The significance level adopted was 5\% ( $p<0.05)$.

The results of experiments determining the cytotoxic effects of denture material conditioned media on epithelial cells and fibroblasts are shown in Tables 1 and 2. In general, the media of unpolished denture disks were found to be more toxic to the cells than their polished counterparts (Tables 1 and 2). Unpolished Valplast conditioned media, was found to be most toxic to both epithelial and fibroblast cells while polished Lucitone media was significantly less toxic, followed by Duraflex ( $p<0.05)$. Only $2 \%$ of epithelial cells and $1 \%$ of fibroblasts were viable after 7 days of incubation with media from unpolished Valplast media, while the polished Valplast media at the same time period (7 days) was less toxic as 92 and $76 \%$ of the epithelial cells and fibroblasts were found to be viable (Tables 1 and 2), respectively. Cells incubated with conditioned media of unpolished disks for 7 days exhibited significantly higher degree of toxicity $(p<0.05)$ than the polished disks.

In general the results of LDH assay appear to agree with MTT cell viability assays. The unpolished Valplast media was found to be toxic to about 84 and $90 \%$ of the epithelial and fibroblast cells respectively while polished Valplast media was toxic to 75 and $77 \%$ of the epithelial and fibroblast cells respectively (Table 3). There were no significant differences in toxicity to the cells caused by the media of polished and unpolished Valplast. Cytotoxicity of Lucitone to cells ranged from 31 to $59 \%$. The 
Table 1: Differences in denture disk conditioned media toxicity to cultured epithelial cells determined by MTT assay. Number of epithelial cells remained viable after incubation with conditioned media (days)

\begin{tabular}{llllll}
\hline $\begin{array}{l}\text { Denture } \\
\text { material }\end{array}$ & 2 days & 3 days & 4 days & 5 days & 7 days \\
\hline Valplast-P & 0 & $540 \pm 45(0.05 \%)$ & $3450 \pm 220(0.35 \%)$ & $12880 \pm 950(1.3 \%)$ & $920450 \pm 72400(92 \%)$ \\
Valplast-UP & 0 & 0 & $2250 \pm 380(0.23 \%)$ & $7350 \pm 810(0.74 \%)$ & $19860 \pm 1090(2 \%)$ \\
Lucitone-P & $8120 \pm 680(0.8 \%)$ & $12650 \pm 1420(1.26 \%)$ & $30600 \pm 3540(3.2 \%)$ & $345000 \pm 32600(34.5 \%)$ & $835500 \pm 72400(84 \%)$ \\
Lucitone-UP & $910 \pm 130(0.09 \%)$ & $3820 \pm 400(0.38 \%)$ & $15750 \pm 175(1.6 \%)$ & $95800 \pm 8420(9.6 \%)$ & $442600 \pm 37550(45 \%)$ \\
Duraflex-P & $7330 \pm 580(0.73 \%)$ & $11300 \pm 1080(1.13 \%)$ & $25200 \pm 3210(2.52 \%)$ & $106350 \pm 9130(10.7 \%)$ & $541450 \pm 42610(54.15 \%)$ \\
Duraflex-UP & $1480 \pm 135(0.15 \%)$ & $7060 \pm 850(0.7 \%)$ & $24050 \pm 1180(2.4 \%)$ & $83920 \pm 6180(8.4 \%)$ & $355300 \pm 33290(35.6 \%)$ \\
\hline
\end{tabular}

P: Polished; UP: Unpolished; The number in parenthesis represents percentage of viable epithelial cells

Table 2: Effect of denture disk conditioned media on viability of gingival fibroblasts determined by MTT assay. Number of fibroblasts remained viable after incubation with conditioned media (days)

\begin{tabular}{llllll}
\hline $\begin{array}{l}\text { Denture } \\
\text { material }\end{array}$ & 2 days & 3 days & 4 days & 5 days & 7 days \\
\hline Valplast-P & 0 & $236 \pm 38(0.24 \%)$ & $3750 \pm 315(0.38 \%)$ & $22500 \pm 1896(2.3 \%)$ & $795000 \pm 68300(76 \%)$ \\
Valplast-UP & 0 & $195 \pm 26(0.02 \%)$ & $2800 \pm 255(0.3 \%)$ & $6420 \pm 595(0.65 \%)$ & $10820 \pm 1220(1.1 \%)$ \\
Lucitone-P & $7080 \pm 810(0.7 \%)$ & $14820 \pm 1510(1.5 \%)$ & $31850 \pm 2955(3.2 \%)$ & $410800 \pm 37550(41 \%)$ & $792950 \pm 70200(79.3 \%)$ \\
Lucitone-UP & $975 \pm 105(0.098 \%)$ & $4340 \pm 390(0.43 \%)$ & $18050 \pm 1645(1.8 \%)$ & $92620 \pm 7930(9.3 \%)$ & $503200 \pm 41975(50.3 \%)$ \\
Duraflex-P & $5990 \pm 485(0.6 \%)$ & $13060 \pm 1245(1.31 \%)$ & $29360 \pm 2610(3 \%)$ & $672030 \pm 9890(6.7 \%)$ & $625500 \pm 54300(63 \%)$ \\
Duraflex-UP & $24560 \pm 310(2.5 \%)$ & $38210 \pm 715(3.8 \%)$ & $57290 \pm 2825(5.7 \%)$ & $86305 \pm 7940(8.6 \%)$ & $382650 \pm 34680(38.3 \%)$ \\
\hline
\end{tabular}

P: Polished; UP: Unpolished; Number in parenthesis represents percentage of viable gingival fibroblasts

Table 3: Cytotoxicity of denture disk conditioned media to human gingival fibroblasts and epithelial cells assessed by LDH release assay. Percentage of cytotoxicity induced at 24 hours

\begin{tabular}{lll}
\hline Denture material & Epithelial cells & Fibroblasts \\
\hline Valplast-P & $74.88 \pm 8.63$ & $76.73 \pm 11.82$ \\
Valplast-UP & $83.94 \pm 7.5$ & $89.66 \pm 13.38$ \\
Lucitone-P & $34.26 \pm 6.14$ & $31.6 \pm 5.97$ \\
Lucitone-UP & $59.2 \pm 8.73$ & $53.8 \pm 10.24$ \\
Duraflex-P & $27.38 \pm 5.81$ & $33.22 \pm 6.15$ \\
Duraflex-UP & $29.46 \pm 6.35$ & $30.59 \pm 6.03$ \\
\hline
\end{tabular}

P: Polished; UP: Unpolished

difference between polished and unpolished Lucitone media toxicity was found to be significant $(\mathrm{p}<0.05)$. Duraflex conditioned media was found to be the least toxic (Table 3). Similar results were also obtained with 2- and 7-day conditioned media (data not shown). The toxicity measured by the LDH assay was calculated based upon the maximum $\mathrm{LDH}$ released from the cells when solubilized with 1\% (W/V) Triton X-100. When the cells were incubated with growth media alone, they spontaneously released approximately $5 \%$ of the maximum LDH activity. The results expressed above were the net percentage of cell toxicity after subtracting the control toxicity values.

The gingival epithelial cells were incubated with growth media and with Valplast unpolished 7-day conditioned media for 4 hours. Since Valplast unpolished conditioned media were found to be most toxic in the MTT and LDH assays, it was chosen for confirming the toxicity using the live/dead mammalian cell viability assay. The cells treated with growth media exhibited a green fluorescence while those treated with Valplast conditioned media exhibited red fluorescence, due to the toxicity. The viability of epithelial cells treated with other conditioned media was found to be unaffected, the cells exhibited green fluorescence (data not shown).

\section{DISCUSSION}

It is customary to investigate the biocompatibility of new dental materials. Allergic and cytotoxic reactions associated with denture materials are well known and include ulcers and burning sensation. ${ }^{10,24}$ This is believed to be caused by close contact of the materials with the host tissue. Thus, tissue response to dental materials is a factor in their selection and usage. With cytotoxic studies it is important to employ the cell lines which closely mimic the host tissues (that come in contact with dental materials). In the present cytotoxic study, we tested both gingival fibroblasts and epithelial cells and compared the cytotoxicity of three types of materials in common use. The differences between polished and unpolished denture materials were also compared, and it was found that the polished surfaces in general appeared to be less toxic than the unpolished denture materials. The null hypothesis in this study (that there is no statistically distinguishable difference) was rejected ( $p>0.05$ ).

This study was conducted using the MTT and LDH assays. The MTT assay is considered by many as a more material-sensitive assay and has been used by several researchers for evaluating resins, as it records the response of one metabolic enzyme. ${ }^{25,26}$ In addition, it is 
simple to use, cost effective, reproducible and easy to interpret, ${ }^{26}$ but as pointed out by Lefebvre et al, ${ }^{25}$ a single assay should not be utilized to determine the true nature of the material.

The MTT assay, LDH assay and live/dead mammalian cell viability assay all demonstrated the acute toxicity of Valplast material. However, there was a decrease in cytotoxicity of polished Valplast conditioned media (as determined by MTT assay) following 7 days of incubation as compared to unpolished Valplast conditioned media. This difference in toxicity of the materials could be associated with the finishing and polishing procedures. ${ }^{25,27}$ It may be during the polishing process that certain toxic elements may become inactive or get removed from the surface layer. ${ }^{27}$ The difference in toxicities seen in different denture base materials at different times is related to composition of the material, degree of polymerization, material density, amount of toxic components eluted, rate of elution and mechanism of toxicity of the eluates. ${ }^{25} \mathrm{Also}$, these clinical problems relate to infection/contamination of the materials, especially by Candida, which then causes the tissue reaction. It is highly likely that the curing process and density of materials may also have played a role in the differences in material cytotoxicity observed in this study. Despite the cytotoxicity of most denture materials, the incidence of allergic responses and hypersensitivity is low, which can be attributed to the presence of a protective layer of keratin overlying the oral mucosal epithelial cells. ${ }^{26}$ Patients are also instructed to place their prostheses in water when outside the mouth resulting in elution of toxic components which may decrease the incidence of hypersensitivity. Moreover, the rate of elution of toxic components decreases with time. ${ }^{26}$

The results of several studies show that maximum toxic effects of resins on oral tissues occurs in the first 48 hours. Therefore, it is recommended that resins should be stored in water for at least 48 hours prior to the delivery of the prosthesis to allow elution of toxic components. ${ }^{9,25}$ Many studies have identified the toxic potential of traditional resin denture base materials due to the release of residual polymerization by-products. Cytological evaluations for the newer denture base materials, specifically for toxicity to gingival epithelial cells and fibroblasts, appear to be novel in the scientific literature. While the main toxic component eluted from the heat acrylic denture base materials is monomer, it would also be interesting to study the nature of the materials eluted from the flexible denture base materials and to study the interaction mechanism between the newer denture base materials and the oral cells. ${ }^{28}$

Determining the toxicity of various denture base materials using cell cultures is simple, easily reproducible and cost effective, ${ }^{28}$ but the results of these tests should be interpreted with caution since cytotoxicity reactions and hypersensitivity cannot be explained in vitro. ${ }^{29}$ Dental materials must be selected based on the results of both in vitro and in vivo studies. ${ }^{29}$ Further studies are needed to investigate the cytotoxicity of the newer flexible denture materials.

The results of this study concluded that Valplast conditioned media in general, especially the media of unpolished disks was found to be most toxic to both cell types. Polishing surfaces appears to aid in reducing the toxicity levels, and the conditioned media from polished disks was significantly less toxic to the cells employed in this study.

\section{CONCLUSION}

The results of the study conclude the following:

- Toxic components may be eluted from all the denture base materials studied including the newer flexible denture base materials.

- The toxicities for cultured cells differ over time.

- Unpolished Valplast conditioned media was the most toxic of all the materials tested.

\section{REFERENCES}

1. Phoenix RD. Denture base materials. Dent Clin North Am 1996;40(1):113-120.

2. Jorge JH, Giampaolo ET, Machado AL, Vergani CE. Cytotoxicity of denture base acrylic resins: a literature review. J Prosthet Dent 2003;90(2):190-193.

3. Hensten-Pettersen A, Wictorin L. The cytotoxic effect of denture base polymers. Acta Odontol Scand 1981;39(2):101-106.

4. Tsuchiya H, Hoshino $Y$, Tajima K, Takagi N. Leaching and cytotoxicity of formaldehyde and methyl methacrylate from acrylic resin denture base materials. J Prosthet Dent 1994;71(2):618-624.

5. Schuster GS, Lefebvre CA, Dirksen TR, Knoernschild KL, Caughman GB. Relationships between denture base resin cytotoxicity and cell lipid metabolism. Int J Prosthodont 1995; 8(6):580.

6. Huang FM, Tai KW, Hu CC, Chang YC. Cytotoxic effects of denture base materials on a permanent human oral epithelial cell line and on primary human oral fibroblasts in vitro. Int J Prosthodont 2001;14(5):439-443.

7. Cimpan MR, Cressey LI, Skaug N, Halstensen A, Lie SA, Gjertsen BT, Matre R. Patterns of cell death induced by eluates from denture base acrylic resins in U-937 human monoblastoid cells. Eur J Oral Sci 2000;108(1):59-69.

8. Vallittu PK, Ekstrand K. In vitro cytotoxicity of fibre-polymethyl methacrylate composite used in dentures. J Oral Rehabil 1999;26(8):666-671.

9. Sheridan PJ, Koka S, Ewoldsen NO, Lefebvre CA, Lavin MT. Cytotoxicity of denture base resins. Int J Prosthodont 1997; 10(1):73-77.

10. Chaves CA, Machado AL, Vergani CE, de Souza RF, Giampaolo ET. Cytotoxicity of denture base and hard chairside reline materials: a systematic review. J Prosthet Dent 2012;107(2): 114-127. 
11. Melilli D, Currò G, Perna AM, Cassaro A. Cytotoxicity of four types of resins used for removable denture bases: in vitro comparative analysis. Minerva Stomatol 2009;58(9):425-434.

12. Ata SO, Yavuzyilmaz H. In vitro comparison of the cytotoxicity of acetal resin, heat-polymerized resin, and autopolymerized resin as denture base materials. J Biomed Mater Res B Appl Biomater 2009;91(2):905-909.

13. Kedjarune U, Charoenworaluk N, Koontongkaew S. Release of methyl methacrylate from heat-cured and autopolymerized resins: cytotoxicity testing related to residual monomer. Aust Dent J 1999;44(1):25-30.

14. Jorge JH, Giampaolo ET, Vergani CE, Machado AL, Pavarina AC, Carlos IZ. Biocompatibility of denture base acrylic resins evaluated in culture of L929 cells. Effect of polymerisation cycle and post-polymerisation treatments. Gerodontol 2007; 24(1):52-57.

15. Jorge JH, Giampaolo ET, Vergani CE, Machado AL, Pavarina AC, Carlos IZ. Effect of post-polymerization heat treatments on the cytotoxicity of two denture base acrylic resins. J Appl Oral Sci 2006;14(3):203-207.

16. Jorge JH, Giampaolo ET, Vergani CE, Machado AL, Pavarina AC, Carlos IZ. Cytotoxicity of denture base resins: effect of water bath and microwave postpolymerization heat treatments. Int J Prosthodont 2004;17(3):340-344.

17. Pund DK, Waliszewski MP, Waliszewski KJ, Berzins D. Survey of partial removable dental prosthesis (partial RDP) types in a distinct patient population. J Prosthet Dent 2011; 106(1):48-56.

18. Glossary of prosthodontic terms. J Prosthet Dent 2005;94(1): 11,36 .

19. Smulow J, Glickman I. An epithelial cell line grown in continuous culture from adult human gingiva. Proc Soc Exp Biol Med 1966;121(4):1294-1296.

20. Sonnenschein C, Smulow J. Karyotypic analysis of an epithelial-like cell line derived from normal adult human gingiva. Exp Cell Res 1966;43(3):633-638.
21. Tipton DA, Pabst MJ, Dabbous MKh. Interleukin 1 B and tumor necrosis factor independent monocyte stimulation of fibroblast collagenase activity. J Cell Biochem 1990;44(4): 253-264.

22. Babich H, Zuckerbraun HL, Barber IB, Babich SB, Borenfreund E. Cytotoxicity of sanguinarine chloride to cultured human cells from oral tissue. Pharmacoly Toxicol 1996;78(6): 397-403.

23. Dong Z, Venkatachalam M, Weinberg J, Saikumar P, Patel Y. Protection of ATP-depleted cells by impermeant strychnine derivatives. Implications for glycine cytoprotection. Am J Patholy 2001;158(3):1021-1028.

24. Machado AL, Giampaolo ET, Vergani CE, Souza JF, Jorge JH. Changes in roughness of denture base and reline materials by chemical disinfection or microwave irradiation: surface roughness of denture base and reline materials. J Appl Oral Sci 2011;19(5):521-528.

25. Lefebvre CA, Knoernschild KL, Schuster GS. Cytotoxicity of eluates from light-polymerized denture base resins. J Prosthet Dent 1994;72(6):644-650.

26. Gonçalves ST, Schmitt MV, Thomas M, de Souza LMA, de Menezes ML. Cytotoxicity of two autopolymerized acrylic resins used in orthodontics. Angle Orthod 2008;78(5): 926-930.

27. Trubiani O, Toniato E, Di Iorio D, Diomede F, Merciaro I, D' Arcangelo C, Caputi S. Morphological analysis and interleukin release in human gingival fibroblasts seeded on different denture base acrylic resins. Int J Immunopathol Pharmacol 2012;25(3):637-643.

28. Jorge JH, Giampaolo ET, Machado AL, Vergani CE. Cytotoxicity of denture base acrylic resins: a literature review. J Prosthet Dent 2003;90(2):190-193.

29. Nakamura M, Kawahara H. Long term biocompatibility test of denture base resins in vitro. J Prosthet Dent 1984;52(5): 694-699. 